\title{
Mechanical Behaviour and Springback Study of an Aluminium Alloy in Warm Forming Conditions
}

\author{
H. Laurent,, ${ }^{1,2}$ J. Coër, ${ }^{1,2}$ R. Grèze, ${ }^{1}$ P. Y. Manach, ${ }^{1}$ A. Andrade-Campos, ${ }^{3}$ \\ M. C. Oliveira, ${ }^{2}$ and L. F. Menezes ${ }^{2}$ \\ ${ }^{1}$ Laboratoire d'Ingénierie des MATériaux de Bretagne (LIMATB-EG2M), Université de Bretagne-Sud, Université Européenne de \\ Bretagne, BP 92116, 56321 Lorient Cedex, France \\ ${ }^{2}$ CEMUC, Departamento de Engenharia Mecânica, Universidade de Coimbra, Polo II, 3030-201 Coimbra, Portugal \\ ${ }^{3}$ Departamento de Engenharia Mecânica, Universidade de Aveiro, Campus Universitrio de Santiago, 3810-193 Aveiro, Portugal
}

Correspondence should be addressed to H. Laurent, herve.laurent@univ-ubs.fr

Received 14 January 2011; Accepted 2 March 2011

Academic Editors: T. K. Basak, Y. He, and K. Sasaki

Copyright $\odot 2011 \mathrm{H}$. Laurent et al. This is an open access article distributed under the Creative Commons Attribution License, which permits unrestricted use, distribution, and reproduction in any medium, provided the original work is properly cited.

This study deals with the mechanical behaviour and material modelling of an AA5754-O alloy at elevated temperature. Experimental shear tests were performed from room temperature up to $200^{\circ} \mathrm{C}$, and the material behaviour has been identified with both shear and tensile tests, as a function of temperature. To analyse the influence of temperature during forming over springback, a split-ring test is used. Experimental results are obtained and compared to numerical simulations performed with the finite element in-house code DD3IMP. The numerical process of ring splitting is performed with the in-house code DD3TRIM. The main observed data are force-displacement curves of the punch during forming, cup thickness at the end of forming, and ring gap after splitting. It is shown that all these parameters are strongly dependent on the forming temperature. A correlation is obtained between experimental data and numerical simulation for the evolution of punch force and opening after springback as a function of temperature. The distribution of the tangential stress in the cup wall is the main factor influencing the springback mechanism in warm forming condition.

\section{Introduction}

One of the most important challenges for the automotive industry in the upcoming years is to meet the demand of reducing the fuel consumption with a simultaneous increase of the safety properties. This can be primarily done by reducing the body weight by substituting traditional steels by aluminium alloys. Aluminium alloys can be formed into parts by a variety of processes similar to those used for steels. However, the formability of aluminium sheet is, under normal processing conditions, lower than that for a typical mild steel. This means that the maximum attainable strain in one process step is less than that for mild steel, along the same deformation path. Hence press operations are often more critical for aluminium than for mild steel.

In order to overcome such problems, good results on the stamping process are obtained for aluminium alloys when the temperature is elevated to an intermediate temperature, below the recrystallisation temperature. This process is called warm forming. The warm press forming of aluminium alloy sheets promoted a great interest and has been studied for several decades. A paper by Takuda et al. [1] contains the first references relating to this subject (see also [2-4]). The research in this domain was accelerated since 1980s [5-12]. A review and discussion of the recent developments on warm forming of aluminium alloys can also be found in $[13,14]$.

It was demonstrated that the formability is improved increasing the uniform temperature, but the best results are obtained by applying temperature gradients. Several investigations showed that the formability with a partial heating in the blank-holder or die area was much better than the obtained with homogeneously heated tools $[2,6$, $7,15,16]$. For example, in deep drawing experiments with an AA5754-O alloy, the limiting drawing ratio could be increased from 2.1 to 2.6 by heating the flange up to $250^{\circ} \mathrm{C}$ and by cooling the punch to room temperature [9]. Several 
research results indicate that up to $200-300 \%$ increase in formability (drawability and elongation) can be achieved by forming aluminium alloys between 200 and $350^{\circ} \mathrm{C}[4,10,14$, $17,18]$.

The formability in warm conditions depends strongly on the composition of the aluminium alloy. For example, 5xxx series alloys (Al-Mg) show better response to warm forming than $6 \mathrm{xxx}$ series alloys (Al-Mg-Si), when deformed in the temperature range of $200-350^{\circ} \mathrm{C}$ [19]. At room temperature, the behaviour of $\mathrm{Al}-\mathrm{Mg}$ alloys is almost independent of the strain rate. Above $100^{\circ} \mathrm{C}$, the tensile strength decreases and the strain rate sensitivity increases. The initial yield stress, however, hardly changes until a temperature of $175^{\circ} \mathrm{C}$. Above $175^{\circ} \mathrm{C}$, the initial yield stress also decreases [9].

Two extra benefits of warm forming are also very interesting for formability of aluminium alloys. Firstly, the stretcher lines (Portevin-Le Chatelier effect) that develop when $\mathrm{Al}-\mathrm{Mg}$ alloys are deformed at room temperature disappear at elevated temperatures. This disadvantage limits the applications of $\mathrm{Al}-\mathrm{Mg}$ alloys to interior automotive panels whereas the Al-Mg-Si alloys are used to perform outer door panel. This leads to recycling issues, since aluminium alloys need to be separated by alloy series in order to produce better-quality recycled alloy. Therefore, the elimination of the appearance of surface marks in $\mathrm{Al}-\mathrm{Mg}$ aluminium can lead to their use in outer automotive panels and improve their recyclability [13].

Another advantage with the warm forming of aluminium alloys is that elevated temperature modifies the stress state in the formed parts, leading to a decrease of springback. Large springback is one of the major drawbacks of aluminium alloy sheets. This is one of the main factors which limit the dissemination of aluminium alloys in the automotive industry $[20,21]$. In recent years, progress has been made on prediction of springback, for example, with respect to the integration in thickness direction, material modelling, geometrical discretization, and so forth [22-26]. However, for the warm forming conditions, a very limited number of studies have been conducted; hence the fundamental understanding of the springback behaviour of aluminium alloys at elevated temperatures is not yet sufficient. Moon et al. [10] investigated the effect of tool temperature on the springback of an aluminium 1050 sheet and showed that the combination of hot die and cold punch could improve the forming quality based on the preliminary experimental results of draw bending process. Keum and Han [27] measured the springback in various forming temperatures by performing draw bending tests for Al 1050 and 5052 alloys. They showed that the springback reduces in warm forming, especially for forming temperatures above $150^{\circ} \mathrm{C}$. Kim and Koç [18] investigate the numerical springback behaviour of an AA5754 aluminium alloy at elevated temperatures for a simple draw bending process. A thermomechanically coupled FEA model has been developed in this study, but the comparison with springback experimental results at elevated temperature was not performed.

The objective of this paper is to present experimental and numerical evaluation of springback in warm forming conditions with an AA5754-O alloy. An original test, named split-ring test, previously used at room temperature [20, 28 ], is performed up to $200^{\circ} \mathrm{C}$. This experimental test consists of a ring sample taken from the sidewall of a flat bottom, deep drawn cup. It provides a simple effective benchmark for correlative forming and springback predictive capabilities with experimental measures. It leads to a large springback, which increases measurement accuracy and reduces experimental errors [29-34]. During all the forming process, the temperature is the same for all tools and is maintained constant. Cutting and splitting operations are made at room temperature. The influence of forming temperature is experimentally evaluated in the punch force evolution of the deep drawn cup. At room temperature, the springback is measured very easily by cutting off a ring and subsequently splitting it. The ring gap after splitting is investigated as a function of temperature. Numerically, the whole deep drawing process is simulated in isothermal conditions using the in-house finite element code DD3IMP [21]. Material parameters are identified using uniaxial tensile and shear tests at different temperatures with the dedicated tool DD3MAT [35]. The stress states in the cup, at the end of drawing, are analysed as a function of temperature. Finally, the main observed data, such as force-displacement curves of the punch during forming, cup thickness, and ring gap after splitting, are investigated as a function of temperature and compared with experimental results.

\section{Material Properties}

An automotive sheet was considered: AA5754-O (Al-Mg) aluminium alloy sheet of $1.0 \mathrm{~mm}$ thick. AA5754-O is mainly used for inner body panels in the automotive industry. The standard composition of the alloy used in this study is listed in Table 1. Both tensile and shear tests were carried out in order to obtain the mechanical properties of the aluminium sheets and also to identify the material parameters of the constitutive law.

2.1. Tensile Tests. Tensile tests were performed at different temperatures (Figure 1). Quasistatic tests were carried out on an Instron 4505 in a heating chamber with a $5 \mathrm{kN}$ load cell. Rectangular samples were of dimensions $20 \times$ $180 \times 1 \mathrm{~mm}^{3}$. The free edges were machined in order to eliminate the hardened area induced by the cutting and, thus, to increase the range of homogeneous deformation. Temperature control during the test was obtained using a thermocouple fixed on the tensile grips. An Instron extensometer (accuracy: $\pm 0.15 \%$, gauge length: $12.5 \mathrm{~mm}$ ) was used to measure the local strain in the heating chamber. It was fixed with specific rubber bands and the signal is compensated in temperature until $200^{\circ} \mathrm{C}$. Strain rate was kept constant at $2 \times 10^{-3} \mathrm{~s}^{-1}$ leading to the same quasistatic conditions as in deep drawing tests $\left(\dot{\bar{\varepsilon}}=3.3 \times 10^{-3} \mathrm{~s}^{-1}\right.$ in the cup wall). Logarithmic strain measures as well as Cauchy stress are calculated.

At room temperature, monotonous tensile tests have been carried out at $0^{\circ}$ (rolling direction (RD), 45 , and $90^{\circ}$ (transverse direction (TD) from the rolling direction 
TABLE 1: Composition in weight \% of aluminium AA5754-O.

\begin{tabular}{lcccccc}
\hline $\mathrm{Cu}$ & $\mathrm{Mn}$ & $\mathrm{Mg}$ & $\mathrm{Si}$ & $\mathrm{Fe}$ & $\mathrm{Cr}$ & $\mathrm{Al}$ \\
\hline$\leq 0.10$ & $\leq 0.500$ & $2.60-3.60$ & $\leq 0.400$ & $\leq 0.400$ & $\leq 0.300$ & $93.6-97.3$ \\
\hline
\end{tabular}

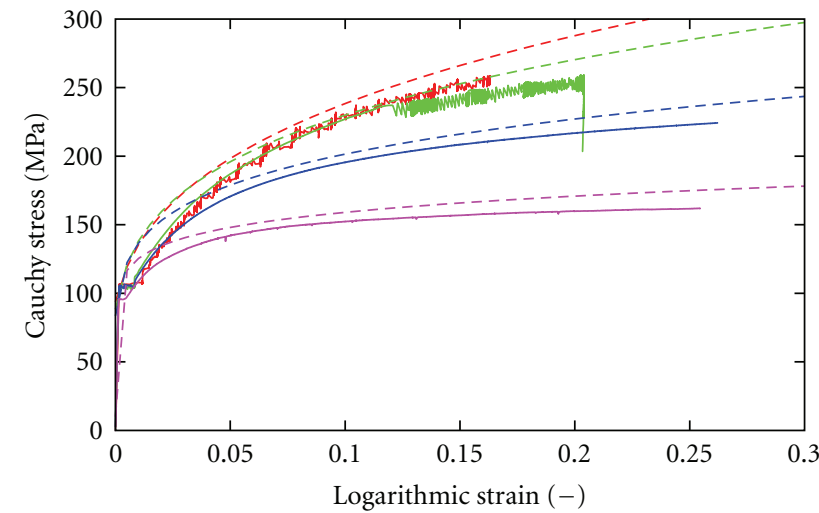

- Experimental: $25^{\circ} \mathrm{C}$

- - - Identification: $25^{\circ} \mathrm{C}$

- Experimental: $150^{\circ} \mathrm{C}$

Experimental: $100^{\circ} \mathrm{C}$

- - Identification: $150^{\circ} \mathrm{C}$

- - Identification: $100^{\circ} \mathrm{C}$

- Experimental: $200^{\circ} \mathrm{C}$

- - Identification: $200^{\circ} \mathrm{C}$

FIGURE 1: Experimental and identified tensile stress-strain curves as a function of temperature.

of the sheet, in order to study the material anisotropy (see [20] for a complete characterisation of this material at room temperature). This alloy presents some oscillations in the stress-strain curves at room temperature. This phenomenon is the so-called Portevin-Le Chatelier (PLC) effect. Serrated flow is associated with repeated propagation of bands of localised plastic deformation, that is, appreciable plastic strain rates only occur within these narrow bands [36-38]. The plastic anisotropy coefficients are determined by fitting the results of the plastic strain in width versus the plastic strain in thickness up to 0.15 of longitudinal strain. The average anisotropy coefficient $\bar{r}=\left(r_{0}+r_{90}+2 r_{45}\right) / 4=$ 0.616 shows a significant normal anisotropy. The planar anisotropy, measured by the coefficient $\Delta r=\left(r_{0}+r_{90}-\right.$ $\left.2 r_{45}\right) / 2=0.0105$, is negligible.

In another study [39], we have shown that a weak temperature dependence of the plastic anisotropy coefficients has been observed from room temperature up to $200^{\circ} \mathrm{C}$, with a relative variation less than $8 \%$.

From Figure 1, it is noticed that the flow stress does not decrease rapidly until the temperature reaches about $100^{\circ} \mathrm{C}$. At a fixed strain rate, flow stress remains constant until the PLC effect disappears with the increase of temperature from $50^{\circ} \mathrm{C}$ to $100^{\circ} \mathrm{C}$, then it decreases rapidly with temperature.

2.2. Shear Tests. The test apparatus consisted of a Shimadzu AG-50kNG instrument adapted for shear testing based on the developments of [40,41] (Figure 2). This apparatus was put in a heating furnace. Samples were rectangular and the dimensions of the gauge area were $L=60 \mathrm{~mm}, h=3 \mathrm{~mm}$, and $e=12 \mathrm{~mm}$. The specimen was positioned in the shear
TABLE 2: Evolution of shear strain correction coefficient as a function of temperature and measurement method.

\begin{tabular}{lcccc}
\hline Temperature & $\gamma_{\exp }$ & $\gamma_{\text {Aramis }}$ & $\gamma_{\text {binocular }}$ & Coef. \\
\hline $25^{\circ} \mathrm{C}$ & 0.25 & 0.18 & 0.18 & 0.72 \\
$25^{\circ} \mathrm{C}$ & 0.5 & 0.37 & 0.34 & 0.75 \\
$150^{\circ} \mathrm{C}$ & 0.5 & 0.41 & 0.36 & 0.82 \\
\hline
\end{tabular}

device and clamped at both sides in such a way that a planar load distribution along the grip length was ensured. When one grip moved downward and the other was fixed, a simple shear deformation was induced in the $3 \mathrm{~mm}$ wide zone $(h)$ between the grips.

The shear stress is determined by $\tau=F / L \cdot e$. To evaluate the shear strain, the relative displacements of two reflecting bands put on the grip system are recorded by a video camera. By dividing this grip displacement by the width of the shear zone, the shear strain is obtained using $\gamma=\tan \alpha=a / h$. This shear strain value is then corrected by a coefficient which takes into account the sliding of the sample under the grips. The value of this coefficient has been identified in function of the temperature by measuring the final strain with two other methods (see Table 2). In the first method, a binocular is used to measure the angle $\alpha$ of a line plotted on the specimen surface before the test and thus the value of $\gamma_{\text {binocular }}$ is obtained. In the second, the shear strain measurement is realized using a noncontacting optical measuring system, ARAMIS, named $\gamma_{\text {aramis. }}$. This coefficient has been estimated at room temperature (at $\gamma$ level of 0.25 and 0.5 ) and at $150^{\circ} \mathrm{C}$ (at $\gamma$ level of 0.5). A coefficient of 0.75 is chosen and taken constant as a function of temperature.

Monotonic uniaxial shear tests have been carried out at several orientations to the RD: $0^{\circ}, 45^{\circ}$, and $90^{\circ}$ at room temperature with a shear strain rate of $\dot{\gamma}=2 \times 10^{-3} \mathrm{~s}^{-1}$ and a maximum shear strain value of about $\gamma=0.4$ (Figure 3 ). Figure 4 shows the shear-strain curves in the RD at different strain rates, at room temperature. As observed in tensile tests $[9,18,20]$, the analysis of this figure indicates that this material exhibits minor shear strain-rate sensitivity at room temperature. Classically, and due to the PLC effect, it is also interesting to notice that this material presents a negative strain rate sensitivity $[11,42,43]$.

The specimen and the grips were put in a furnace with a controlled temperature by thermocouples fixed on both the specimen and the grips. Similarly to tensile tests, shear tests were performed for several temperatures in the range of $25-200^{\circ} \mathrm{C}$, with the results of three tests averaged for each temperature. It should be mentioned that only small variations in the stress-strain behaviour were noticed between the three tests for each temperature.

Figure 5 presents the shear-strain curves in the RD at several temperatures. It is observed that the difference 


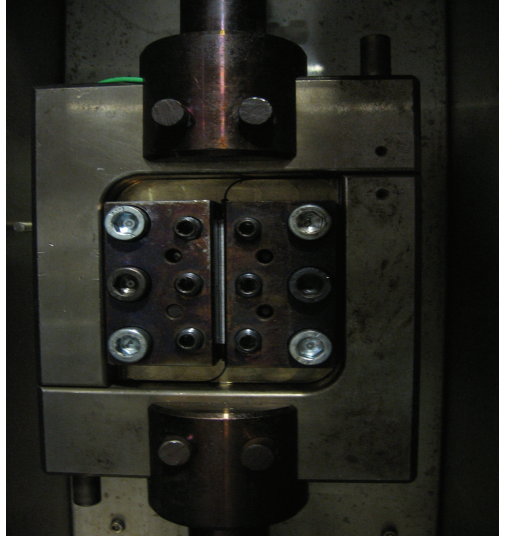

(a)

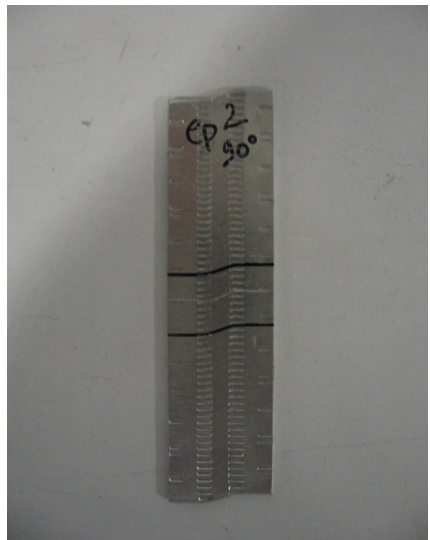

(b)

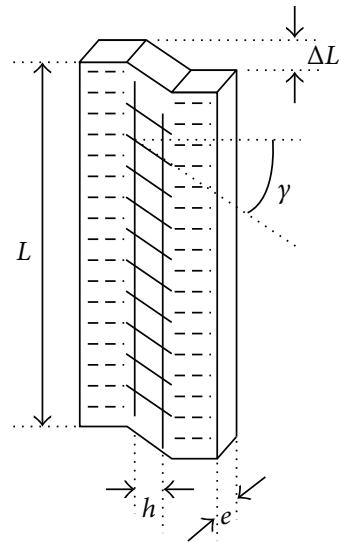

(c)

FIgURE 2: Shear test device and sketch of the specimen.

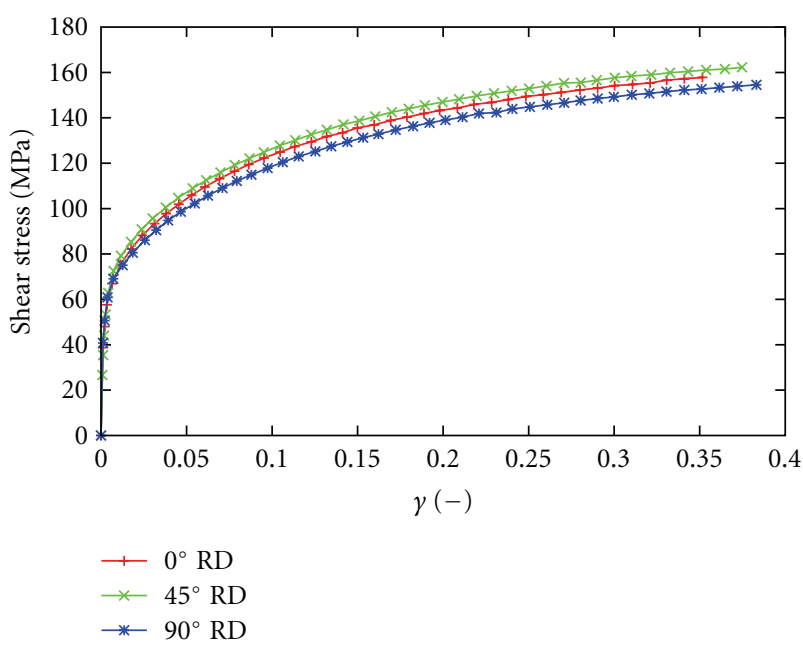

FIGURE 3: Shear stress versus shear strain curves at $0^{\circ}, 45^{\circ}$, and $90^{\circ}$ to the $\mathrm{RD}$ at room temperature.

between the curves at room temperature and at $100^{\circ} \mathrm{C}$ is rather small. Above $150^{\circ} \mathrm{C}$, the ultimate shear stress decreases with increasing temperature. It is also interesting to notice that a peculiar effect, similar to PLC effect, appears at $100^{\circ} \mathrm{C}$ after a strain level of about $\gamma=0.25$. The same phenomenon appears in tensile tests for this temperature (Figure 1) for a tensile strain level of 0.12 .

\section{Experimental}

An experimental device has been used to perform the drawing of cylindrical cups $[20,44]$. Tools geometry is given in Table 3. Deep drawing tests are performed in a heating furnace with a controlled temperature, in the range from $25^{\circ} \mathrm{C}$ to $200^{\circ} \mathrm{C}$.

The punch force-displacement curves as a function of the temperature are shown in Figure 6. The maximum force reached at room temperature is $55 \mathrm{kN}$ at a displacement of $24 \mathrm{~mm}$. The test was stopped at $60 \mathrm{~mm}$, when the blank

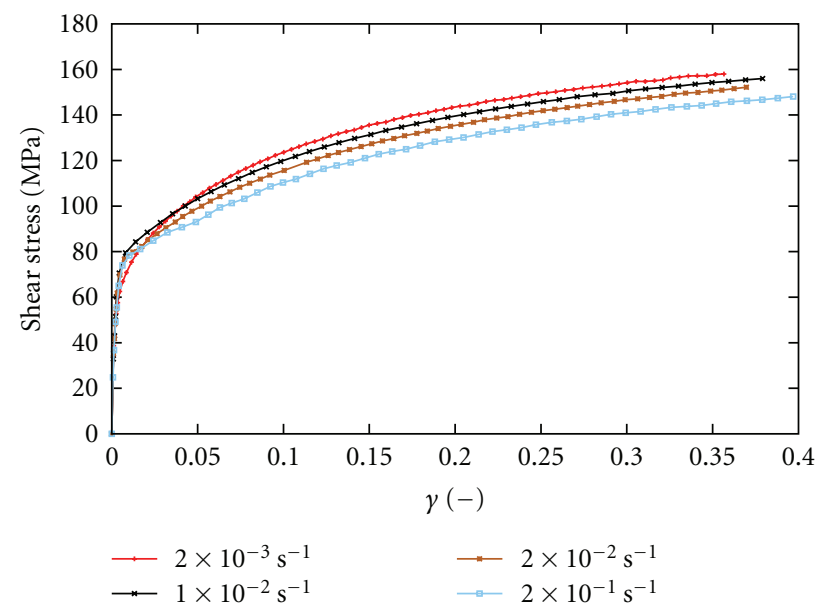

FIGURE 4: Strain rate influence in shear stress versus shear strain curves in the $\mathrm{RD}$ at room temperature.

TABLE 3: Drawing tool geometry and process parameters.

\begin{tabular}{lc}
\hline Die opening diameter $(\mathrm{mm})$ & 104.5 \\
\hline Die radius $(\mathrm{mm})$ & 8 \\
Punch diameter $(\mathrm{mm})$ & 100 \\
Punch radius $(\mathrm{mm})$ & 5.5 \\
Blank-holder opening diameter $(\mathrm{mm})$ & 104.5 \\
Blank-holder force $(\mathrm{Kn})$ & 24 \\
Punch speed $(\mathrm{mm} / \mathrm{s})$ & 0.5 \\
Blank diameter $(\mathrm{mm})$ & 170 \\
Blank thickness $(\mathrm{mm})$ & 1 \\
\hline
\end{tabular}

was fully drawn. With the increase of the temperature, the maximum force reached during the drawing step drops down to $34 \mathrm{kN}$. The force decreases with the increase of the temperature.

Subsequent to this, thickness profiles were measured, using a 3D measuring machine, along the cup wall in the 


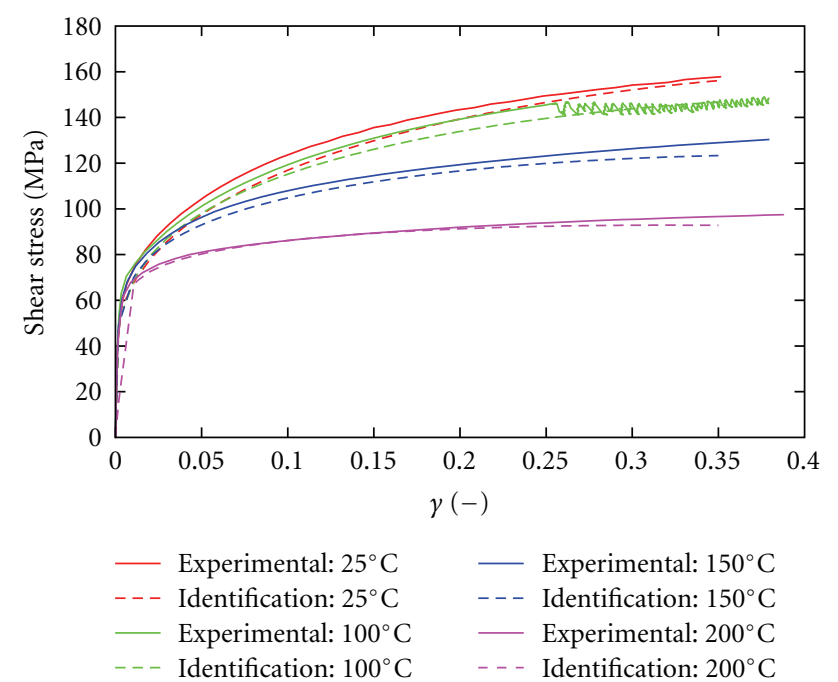

FIGURE 5: Experimental and identified shear stress versus shear strain curves in the $\mathrm{RD}$ as a function of temperature.

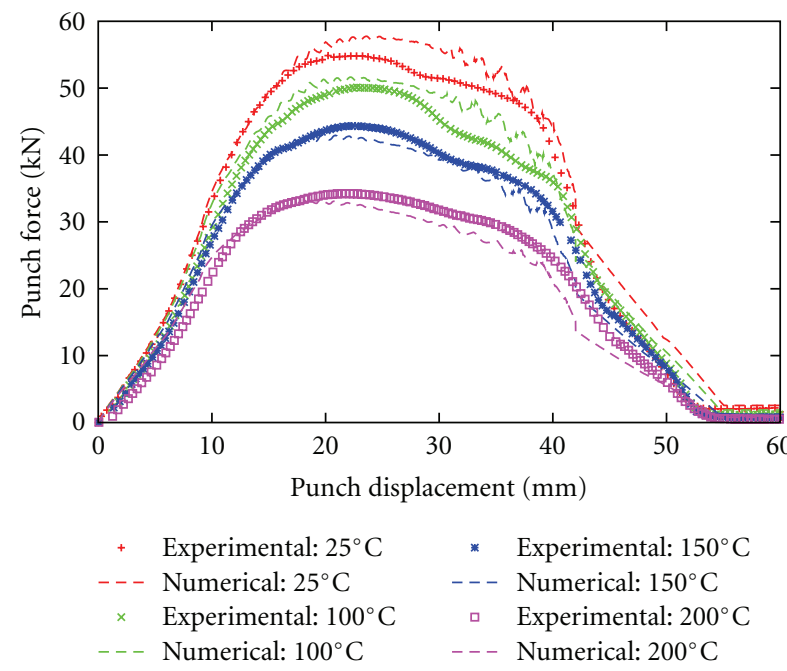

FIGURE 6: Experimental and numerical punch force-displacement curves as a function of temperature.

$\mathrm{RD}$ (Figure 7). A thinning of the sheet is noticed below a height of around $25 \mathrm{~mm}$ (between $5 \mathrm{~mm}$ and $25 \mathrm{~mm}$ ) and a thickening above. Such an evolution is typical of a deformation process by extension.

Finally, experimental springback data consist of ring gap measurement along straight lines connecting the two ends of the split rings. For all tests, cutting and splitting operations were made at room temperature. The cups are $20 \mathrm{~mm}$ high and have an internal diameter of $100 \mathrm{~mm}$ before splitting. Rings are cut at a height of $15 \mathrm{~mm}$ from the cup bottom by turning. As already mentioned in [33], it was found that as long as the deformation resulting from the cutting method is localised in a small section of the ring, whatever by shear or material removal, the resulting opening is unaffected.

Three springback tests have been performed at each temperature. The measured openings of rings as a function of

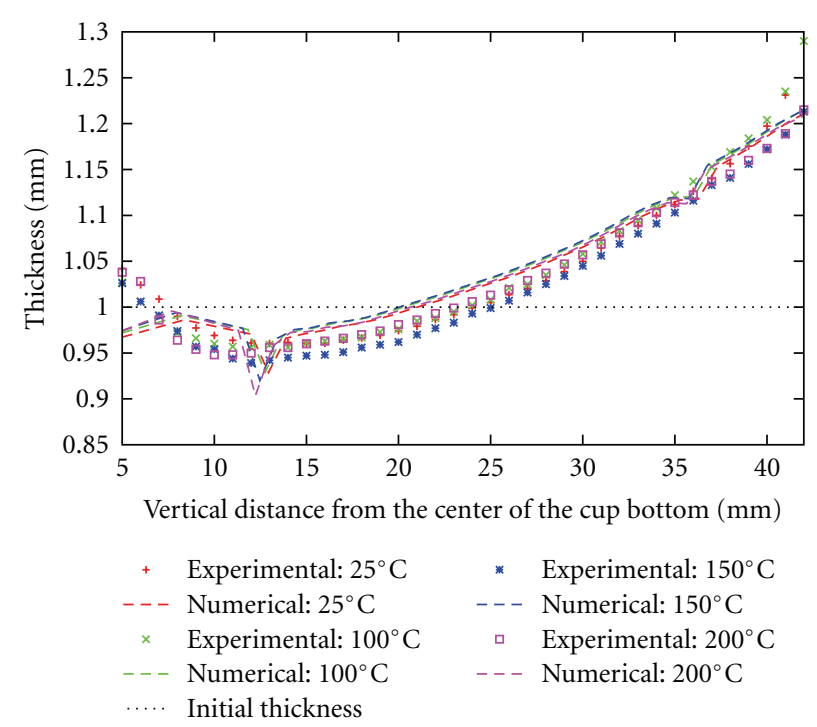

Figure 7: Experimental and numerical thickness evolution as a function of the distance from the cup bottom as a function of temperature.

TABLE 4: Experimental and numerical opening of the ring as a function of temperature.

\begin{tabular}{lcccc}
\hline Temperature $\left({ }^{\circ} \mathrm{C}\right)$ & 25 & 100 & 150 & 200 \\
\hline Experimental opening $(\mathrm{mm})$ & 64 & 51 & 37 & 21 \\
Numerical opening $(\mathrm{mm})$ & 65 & 56.2 & 46 & 27.6 \\
\hline
\end{tabular}

temperature are given in Table 4. Opening gap after splitting is about $64 \mathrm{~mm}$ wide $( \pm 3 \mathrm{~mm})$ at room temperature. It is rather constant from room temperature up to about $100^{\circ} \mathrm{C}$, but then it decreases down to about $21 \mathrm{~mm}$ at $200^{\circ} \mathrm{C}$. It has to be noticed that the shape of the ring after splitting is slightly conical along the height direction due to the variation of thickness and the nonsymmetric stress distribution in ring's wall [20]. The tendency of springback reduction at elevated temperatures can be observed from the shape change after springback for different temperatures shown in Figure 8.

\section{Numerical Simulation}

Numerical simulations of the cup drawing are performed with the in-house DD3IMP code [21], to predict material deformation during forming and springback, after splitting. The main goal of this paper is to analyse the influence of the temperature on the springback phenomenon in quasistatic and isothermal conditions. In order to obtain preliminary numerical results to be compared to experimental results, this study is a first step to the numerical simulation of this complex forming process in coupled thermomechanical conditions. Thus, as for experimental tests, all numerical simulations are performed in isothermal conditions. The ring splitting is numerically performed in isothermal conditions without taking into account the cooling after forming. 


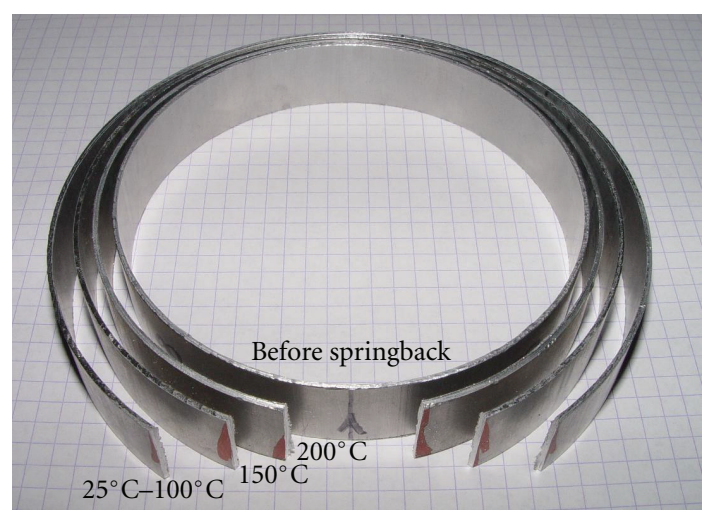

FIGURE 8: Opening of the rings for several temperatures in the range $25-200^{\circ} \mathrm{C}$.

Even if viscous effect can be significant at elevated temperature, the influence of strain rate and coupled temperaturedisplacement formulation is not currently taken into account in this paper. The analysis of these phenomena is actually in progress in the DD3IMP code.

The blank is meshed with $3 \mathrm{D}$ isoparametric hexahedral elements with selective reduced integration. The type and the number of elements and nodes were first optimised in a parametric study [28]. For symmetry reasons, only a quarter of the blank is considered. 6304 elements are used with two layers in the thickness direction (Figure 9). In order to produce half-part of the ring, a mirror operation is performed at the end of the deep drawing simulation.

The blank-holder force is kept constant at $6 \mathrm{kN}$ during the drawing stage, and the blank is drawn down to $60 \mathrm{~mm}$ with a constant punch speed of $0.5 \mathrm{~mm} \cdot \mathrm{s}^{-1}$. An oil lubricant is applied manually to both sides of the blank (Yushrio Former FD-1500 at room temperature and Jelt above). The friction coefficient has been identified numerically by inverse method on the punch-force displacement curve. It is fit in the last step of the forming stage when the top of the cup slides along the wall of the drawing die, that is, when the final force plateau is observed. The friction coefficient decreases in function of temperature: $0.15,0.12,0.1$, and 0.09 for 25,100 , 150 , and $200^{\circ} \mathrm{C}$, respectively.

Inverse identification of material parameters is performed with the dedicated tool DD3MAT (also of the DD3 family code [35]). The database is composed of stressstrain curves from tensile and shear tests in the $\mathrm{RD}$ for temperature ranges of $25-200^{\circ} \mathrm{C}$ presented in Section 2. Mechanical properties used for the numerical simulation are given in Table 5.

The constitutive behaviour is described by an isotropic hardening law of the Swift type:

$$
\bar{\sigma}=K\left(\varepsilon_{0}+\bar{\varepsilon}^{p}\right)^{n},
$$

where $\bar{\sigma}$ is the equivalent stress, $\bar{\varepsilon}^{p}$ is the equivalent plastic strain, $\varepsilon_{0}=\left(\sigma_{0} / K\right)^{1 / n}$, and $K, n$, and $\sigma_{0}$ are material parameters determined from the mechanical tests.

In this paper, the von Mises yield isotropic criterion is adopted. This choice is due to several reasons. Firstly, that this criterion leads to numerical simulations of the split-ring test which are in good agreement with experimental results at room temperature $[20,28]$. Secondly, the anisotropy of the yield stress is rather limited even if it is larger for the plastic anisotropy ratios. Finally, as we have mentioned before, new tensile tests results, performed at elevated temperatures, show that the material anisotropy, observed at room temperature, is not affected by the temperature until $200^{\circ} \mathrm{C}[39]$.

Poisson's ratio is considered constant in this temperature range and fixed to $v=0.33$. On the other hand, Young's modulus is not constant as a function of the temperature and follows the evolution given in Table 5 .

Figures 6 and 7 compare the experimental with numerical simulation results. In the case of punch forcedisplacement evolution, a good agreement between numerical simulation and experimental results is observed. Significant force oscillations are observed after $33 \mathrm{~mm}$ depth in all simulations, which is due to the flow into the die radius zone of finite element with higher in-plane size. The differences between experimental and numerical results are in the same order of magnitude for all temperatures. In the case of thickness distribution in the cup wall (Figure 7), the thickness presents a slight oscillation near $12 \mathrm{~mm}$ and $35 \mathrm{~mm}$ of the cup wall, due to the transition of the in-plane element size at these positions (see mesh type in Figure 9). Thickness is overestimated for all temperatures. But, as the blank-holder force has been kept at the same level for all tests, the increase of temperature tends to slightly decrease the thickness due to higher restraining forces compared to yield stress.

After removing the tools, the DD3TRIM program [45, 46] (part of the DD3 family code) is used to perform the ring cutting phases. This code allows the geometrical treatment of cutting solid isoparametric hexahedral element meshes and the determination of the material state with the remapping. For the geometrical treatment, the implemented strategy consists, firstly, in evaluating the elements that are to be eliminated/kept with the trimming procedure and, then, adjusting the boundary's remaining affected elements to the desired geometry. This adjustment is done by a node stretching technique, for two projection schemes, with optimisation of the final element shape at the boundary. The material state variables are transferred from the original untrimmed mesh to the new one, through an interpolation scheme $[28,45]$. The ring is finally split by removing a symmetry boundary condition at one of the ring ends, and the springback is then calculated by relaxation of the part (Figure 9).

An advantage of using DD3TRIM program is that the ring's height is exact. This is not the case of the previous numerical simulations [20] where the original mesh was partitioned to anticipate the ring final size.

Table 4 presents the numerical results of the opening according to the temperature. Numerical value of opening is closed to the experimental ones at room temperature but the relative errors of the numerical results with respect to the experimental ones increase with the temperature to reach an error of $31.4 \%$ at $200^{\circ} \mathrm{C}$. 


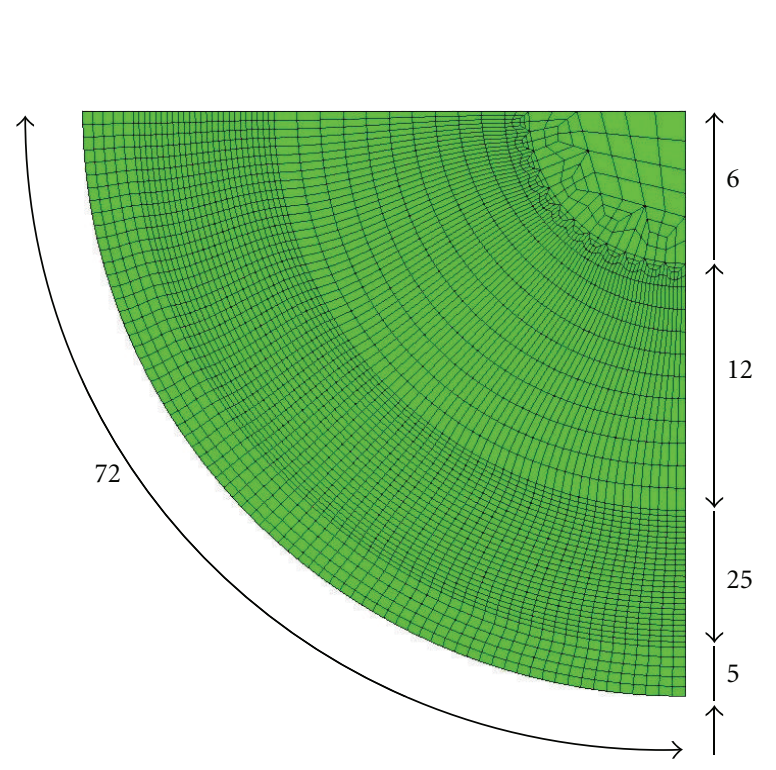

(a)

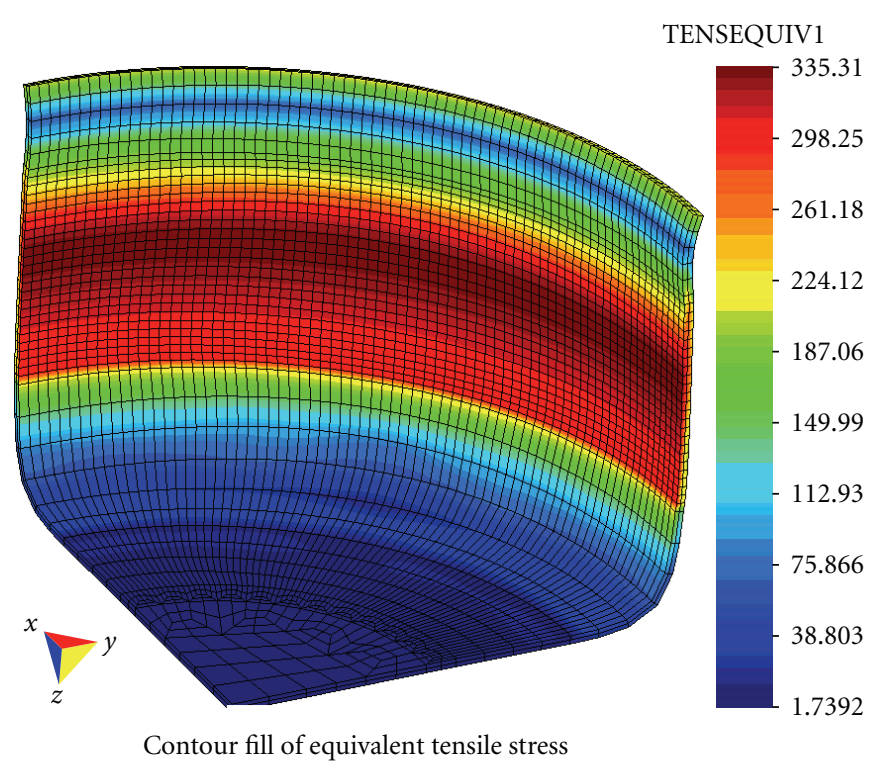

(b)

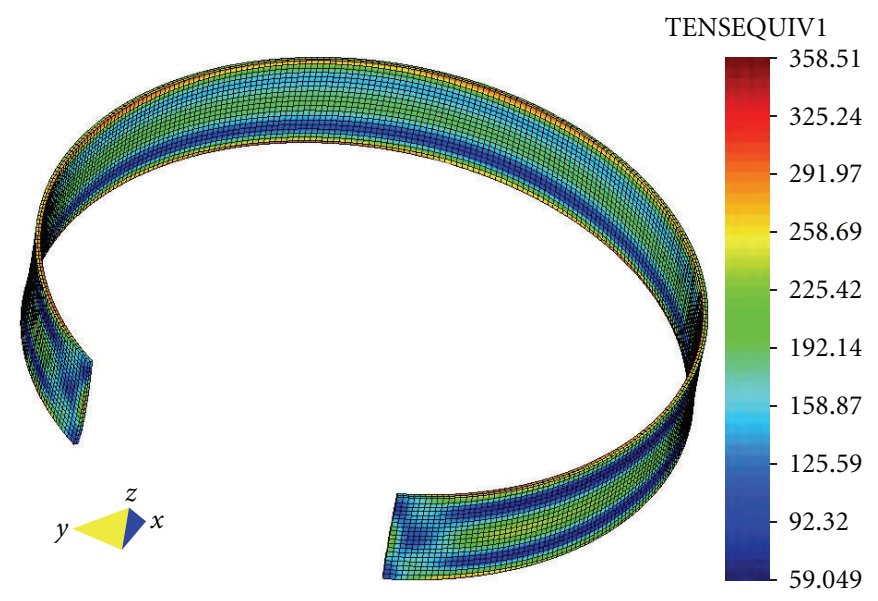

Contour fill of equivalent tensile stress

(c)

FIGURE 9: (a) Mesh used in the simulation; (b) equivalent stress distribution in the drawn cup; (c) opening of the mesh after cutting.

TABLE 5: Mechanical properties of the AA5754-O alloy.

\begin{tabular}{lcccc}
\hline & \multicolumn{3}{c}{ Temperature $\left({ }^{\circ} \mathrm{C}\right)$} \\
\hline Young's modulus $(\mathrm{GPa})$ & 25 & 100 & 150 & 200 \\
\hline Poisson's ratio & 70.4 & 70.4 & 67.2 & \\
\hline$\varepsilon_{0}$ & & & 0.33 & \\
$K(\mathrm{MPa})$ & $3.69 \times 10^{-3}$ & $1.80 \times 10^{-3}$ & $0.625 \times 10^{-3}$ & $2.39 \times 10^{-13}$ \\
$n$ & 449.2 & 395.2 & 300 & 201.8 \\
\hline
\end{tabular}

The blank thickness varies as a result of the material flow into the die cavity. Consequently, the accumulated strain also changes for different locations in the cup. The accumulated strain has direct impact on the throughthickness circumferential stress distribution. These stresses play a key role in the springback modelling because their integral over the thickness yields a nonzero bending moment and, thus, a change of shape [20, 32-34, 47].

Therefore, to further investigate the origin of the springback, through-thickness stress distribution before cutting is analysed. The tangential stress has pronounced contribution towards springback, while the radial stress has 


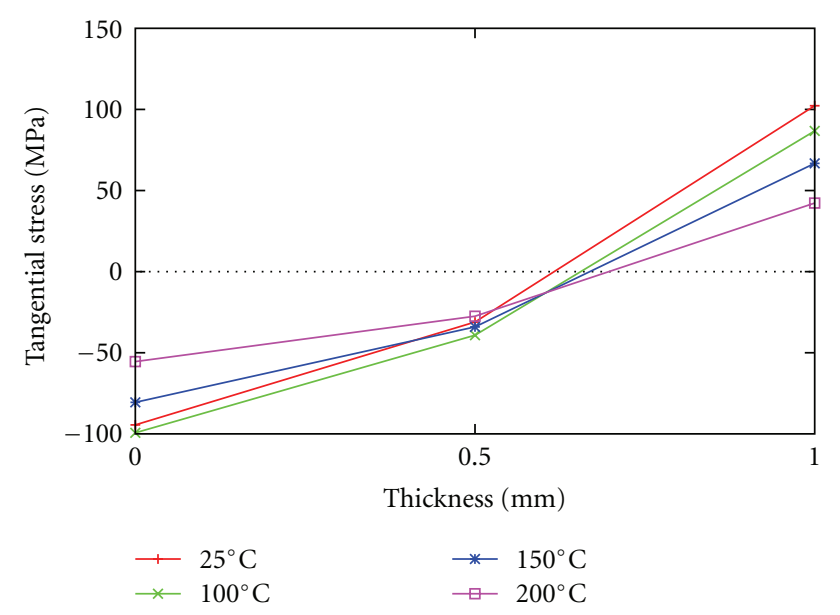

FIGURE 10: Through-thickness tangential stress distribution at midheight of the cut ring as a function of temperature.

a weak influence [20]. For this reason, only the tangential stresses are analysed in the following.

Figure 10 presents the through-thickness tangential stresses $\left(\sigma_{\theta \theta}\right)$ for all temperatures at mid-height of the drawn cup. Results are presented in the transverse direction (TD). Thickness 0 corresponds to the inner part of the cup and thickness 1 to the outer part. With all temperatures, it is observed that the inner skin is in a compressive stress state, whereas the outer skin is in tension. This characteristic stress state before unloading leads to a bending moment and, hence, to a large amount of springback. In addition, it is observed that the difference of tensile and compressive stresses decreases as temperature increases. The main reason can be attributed to the lower material strength of the aluminium alloy at elevated temperatures, which results in a smaller residual bending moment after deep drawing and ring opening after springback.

\section{Conclusions}

The experimental study of the split-ring test on a AA5754-O aluminium alloy for several temperatures in the range of 25 $200^{\circ} \mathrm{C}$ is presented. These experimental results are compared to numerical simulations performed with the finite element code DD3IMP. Material parameters are identified using uniaxial tensile and shear tests at different temperatures. Warm temperature condition reduces the maximum punch force needed for the forming of the cup. A correlation is obtained between experimental data and numerical simulation for the evolution of punch force and opening after springback as a function of temperature. The stress distribution in the thickness of the cup shows that the effect of temperature tends to decrease the stress gradient in the cup wall, which is directly linked to the decrease of the springback opening of the ring. The distribution of the tangential stress in the cup wall is the main factor influencing the springback mechanism in warm forming condition.

\section{Acknowledgments}

This research was supported by the "Région Bretagne" (France), the European Union, and a Marie Curie IntraEuropean Fellowship within the 7th European Community Framework Programme (PIEF-GA-2008-220688).

\section{References}

[1] H. Takuda, K. Mori, I. Masuda, Y. Abe, and M. Matsuo, "Finite element simulation of warm deep drawing of aluminium alloy sheet when accounting for heat conduction," Journal of Materials Processing Technology, vol. 120, no. 1-3, pp. 412-418, 2002.

[2] D. Finch, S. Wilson, and J. Dorn, "Deep-drawing aluminum alloys at elevated temperatures," ASM Transactions, vol. 36, pp. 254-289, 1946.

[3] R. A. Ayres, "Alloying aluminum with magnesium for ductility at warm temperatures $\left(250^{\circ} \mathrm{C}\right)$," Metallurgical Transactions A, vol. 10, no. 7, pp. 849-854, 1979.

[4] F. Shehata, M. J. Painter, and R. Pearce, "Warm forming of aluminium/magnesium alloy sheet," Journal of Mechanical Working Technology, vol. 2, no. 3, pp. 279-290, 1978.

[5] E. M. Taleff, G. A. Henshall, D. R. Lesuer, and T. G. Nieh, "Warm formability of aluminum-magnesium alloys," in Proceedings of the 4th international conference of aluminum alloys, Atlanta, Ga, USA, 1994.

[6] T. Naka and F. Yoshida, "Deep drawability of type 5083 aluminium-magnesium alloy sheet under various conditions of temperature and forming speed," Journal of Materials Processing Technology, vol. 89-90, pp. 19-23, 1999.

[7] P. J. Bolt, N. A. P. M. Lamboo, and P. J. C. M. Rozier, "Feasibility of warm drawing of aluminium products," Journal of Materials Processing Technology, vol. 115, no. 1, pp. 118-121, 2001.

[8] T. Naka, G. Torikai, R. Hino, and F. Yoshida, "The effects of temperature and forming speed on the forming limit diagram for type 5083 aluminum-magnesium alloy sheet," Journal of Materials Processing Technology, vol. 113, no. 1-3, pp. 648-653, 2001.

[9] A. van den Boogaard, Thermally enhanced forming of aluminum sheet-modeling and experiments, Ph.D. thesis, Twente University, Enschede, The Netherlands, 2002.

[10] Y. H. Moon, S. S. Kang, J. R. Cho, and T. G. Kim, "Effect of tool temperature on the reduction of the springback of aluminum sheets," Journal of Materials Processing Technology, vol. 132, no. 1-3, pp. 365-368, 2003.

[11] A. H. van den Boogaard and J. Huétink, "Simulation of aluminium sheet forming at elevated temperatures," Computer Methods in Applied Mechanics and Engineering, vol. 195, no. 48-49, pp. 6691-6709, 2006.

[12] N. Abedrabbo, F. Pourboghrat, and J. Carsley, "Forming of AA5182-O and AA5754-O at elevated temperatures using coupled thermo-mechanical finite element models," International Journal of Plasticity, vol. 23, no. 5, pp. 841-875, 2007.

[13] P. A. Tebbe and G. T. Kridli, "Warm forming of aluminium alloys: an overview and future directions," International Journal of Materials and Product Technology, vol. 21, no. 1-3, pp. 24-40, 2004.

[14] S. Toros, F. Ozturk, and I. Kacar, "Review of warm forming of aluminum-magnesium alloys," Journal of Materials Processing Technology, vol. 207, no. 1-3, pp. 1-12, 2008.

[15] D. Li and A. K. Ghosh, "Biaxial warm forming behavior of aluminum sheet alloys," Journal of Materials Processing Technology, vol. 145, no. 3, pp. 281-293, 2004. 
[16] G. Palumbo and L. Tricarico, "Numerical and experimental investigations on the Warm Deep Drawing process of circular aluminum alloy specimens," Journal of Materials Processing Technology, vol. 184, no. 1-3, pp. 115-123, 2007.

[17] H. S. Kim, M. Koç, J. Ni, and A. Ghosh, "Finite element modeling and analysis of warm forming of aluminum alloysvalidation through comparisons with experiments and determination of a failure criterion," Journal of Manufacturing Science and Engineering, vol. 128, no. 3, pp. 613-621, 2006.

[18] H. S. Kim and M. Koç, "Numerical investigations on springback characteristics of aluminum sheet metal alloys in warm forming conditions," Journal of Materials Processing Technology, vol. 204, no. 1-3, pp. 370-383, 2008.

[19] D. Li and A. Ghosh, "Tensile deformation behavior of aluminum alloys at warm forming temperatures," Materials Science and Engineering A, vol. 352, no. 1-2, pp. 279-286, 2003.

[20] H. Laurent, R. Grèze, P. Y. Manach, and S. Thuillier, "Influence of constitutive model in springback prediction using the splitring test," International Journal of Mechanical Sciences, vol. 51, no. 3, pp. 233-245, 2009.

[21] M. C. Oliveira, J. L. Alves, B. M. Chaparro, and L. F. Menezes, "Study on the influence of work-hardening modeling in springback prediction," International Journal of Plasticity, vol. 23, no. 3, pp. 516-543, 2007.

[22] L. Geng and R. H. Wagoner, "Role of plastic anisotropy and its evolution on springback," International Journal of Mechanical Sciences, vol. 44, no. 1, pp. 123-148, 2002.

[23] Z. Dongjuan, C. Zhenshan, R. Xueyu, and L. Yuqiang, "Sheet springback prediction based on non-linear combined hardening rule and Barlat89's yielding function," Computational Materials Science, vol. 38, no. 2, pp. 256-262, 2006.

[24] M. Firat, B. Kaftanoglu, and O. Eser, "Sheet metal forming analyses with an emphasis on the springback deformation," Journal of Materials Processing Technology, vol. 196, no. 1-3, pp. 135-148, 2008.

[25] B. Haddag, T. Balan, and F. Abed-Meraim, "Investigation of advanced strain-path dependent material models for sheet metal forming simulations," International Journal of Plasticity, vol. 23, no. 6, pp. 951-979, 2007.

[26] T. B. Stoughton and J. W. Yoon, "Anisotropic hardening and non-associated flow in proportional loading of sheet metals," International Journal of Plasticity, vol. 25, no. 9, pp. 1777-1817, 2009.

[27] Y. T. Keum and B. Y. Han, "Springback of FCC sheet in warm forming," Journal of Ceramic Processing Research, vol. 3, no. 3, pp. 159-165, 2002.

[28] H. Laurent, R. Grèze, M. C. Oliveira, L. F. Menezes, P. Y. Manach, and J. L. Alves, "Numerical study of springback using the split-ring test for an AA5754 aluminum alloy," Finite Elements in Analysis and Design, vol. 46, no. 9, pp. 751-759, 2010.

[29] Z. C. Xia, C. E. Miller, and F. Ren, "Springback behavior of AA6111-T4 with split-ring test," in Proceedings of the 8th International Conference on Numerical Methods in Industrial Forming Processes (NUMIFORM '04), J. C. C. S. Ghosh and J. Lee, Eds., vol. 712 of AIP Conference Proceedings, pp. 934-939, June 2004.

[30] R. Echempati and V. M. S. S. Dev, "Spring back studies in aluminium alloys," in Society of Automotive Engineers, vol. 011057, Inc., New York, NY, USA, 2002.

[31] C. W. Hsu, A. G. Ulsoy, and M. Y. Demeri, "Development of process control in sheet metal forming," Journal of Materials Processing Technology, vol. 127, no. 3, pp. 361-368, 2002.

[32] T. Gnaeupel-Herold, H. J. Prask, R. J. Fields, T. J. Foecke, Z. C. $\mathrm{Xia}$, and U. Lienert, "A synchrotron study of residual stresses in a Al6022 deep drawn cup," Materials Science and Engineering A, vol. 366, no. 1, pp. 104-113, 2004.

[33] T. Foecke and T. Gnaeupel-Herold, "Robustness of the sheet metal springback cup test," Metallurgical and Materials Transactions A, vol. 37, no. 12, pp. 3503-3510, 2006.

[34] Z. C. Xia, C. E. Miller, and F. Ren, "Experimental and numerical investigations of a split-ring test for springback," Journal of Manufacturing Science and Engineering, vol. 129, no. 2, pp. 352-359, 2007.

[35] B. M. Chaparro, S. Thuillier, L. F. Menezes, P. Y. Manach, and J. V. Fernandes, "Material parameters identification: gradient-based, genetic and hybrid optimization algorithms," Computational Materials Science, vol. 44, no. 2, pp. 339-346, 2008.

[36] R. C. Picu, G. Vincze, F. Ozturk, J. J. Gracio, F. Barlat, and A. M. Maniatty, "Strain rate sensitivity of the commercial aluminum alloy AA5182-O," Materials Science and Engineering A, vol. 390, no. 1-2, pp. 334-343, 2005.

[37] H. Halim, D. S. Wilkinson, and M. Niewczas, "The PortevinLe Chatelier (PLC) effect and shear band formation in an AA5754 alloy," Acta Materialia, vol. 55, no. 12, pp. 4151-4160, 2007.

[38] T. Böhlke, G. Bondár, Y. Estrin, and M. A. Lebyodkin, “Geometrically non-linear modeling of the Portevin-Le Chatelier effect," Computational Materials Science, vol. 44, no. 4, pp. 1076-1088, 2009.

[39] J. Coër, C. Bernard, H. Laurent, A. Andrade-Campos, and S. Thuillier, "The effect of temperature on anisotropy properties of an aluminium alloy," Experimental Mechanics, 2010.

[40] J. J. Gracio, F. Barlat, E. F. Rauch, P. T. Jones, V. F. Neto, and A. B. Lopes, "Artificial aging and shear deformation behaviour of 6022 aluminium alloy," International Journal of Plasticity, vol. 20, no. 3, pp. 427-445, 2004.

[41] J. W. Yoon, F. Barlat, J. J. Gracio, and E. Rauch, "Anisotropic strain hardening behavior in simple shear for cube textured aluminum alloy sheets," International Journal of Plasticity, vol. 21, no. 12, pp. 2426-2447, 2005.

[42] A. Benallal, T. Berstad, T. Børvik, O. S. Hopperstad, I. Koutiri, and R. N. de Codes, "An experimental and numerical investigation of the behaviour of AA5083 aluminium alloy in presence of the Portevin-Le Chatelier effect," International Journal of Plasticity, vol. 24, no. 10, pp. 1916-1945, 2008.

[43] H. Jiang, Q. Zhang, X. Chen et al., “Three types of Portevin-Le Chatelier effects: experiment and modelling," Acta Materialia, vol. 55, no. 7, pp. 2219-2228, 2007.

[44] S. Thuillier, P. Y. Manach, L. F. Menezes, and M. C. Oliveira, "Experimental and numerical study of reverse re-drawing of anisotropic sheet metals," Journal of Materials Processing Technology, vol. 125-126, pp. 764-771, 2002.

[45] A. J. Baptista, J. L. Alves, D. M. Rodrigues, and L. F. Menezes, "Trimming of 3D solid finite element meshes using parametric surfaces: application to sheet metal forming," Finite Elements in Analysis and Design, vol. 42, no. 12, pp. 1053-1060, 2006.

[46] R. Padmanabhan, M. C. Oliveira, A. J. Baptista, J. L. Alves, and L. F. Menezes, "Numerical study on the influence of initial anisotropy on optimal blank shape," Finite Elements in Analysis and Design, vol. 45, no. 2, pp. 71-80, 2009.

[47] T. Gnaeupel-Herold, T. Foecke, H. J. Prask, and R. J. Fields, "An investigation of springback stresses in AISI-1010 deep drawn cups," Materials Science and Engineering A, vol. 399, no. 1-2, pp. 26-32, 2005. 

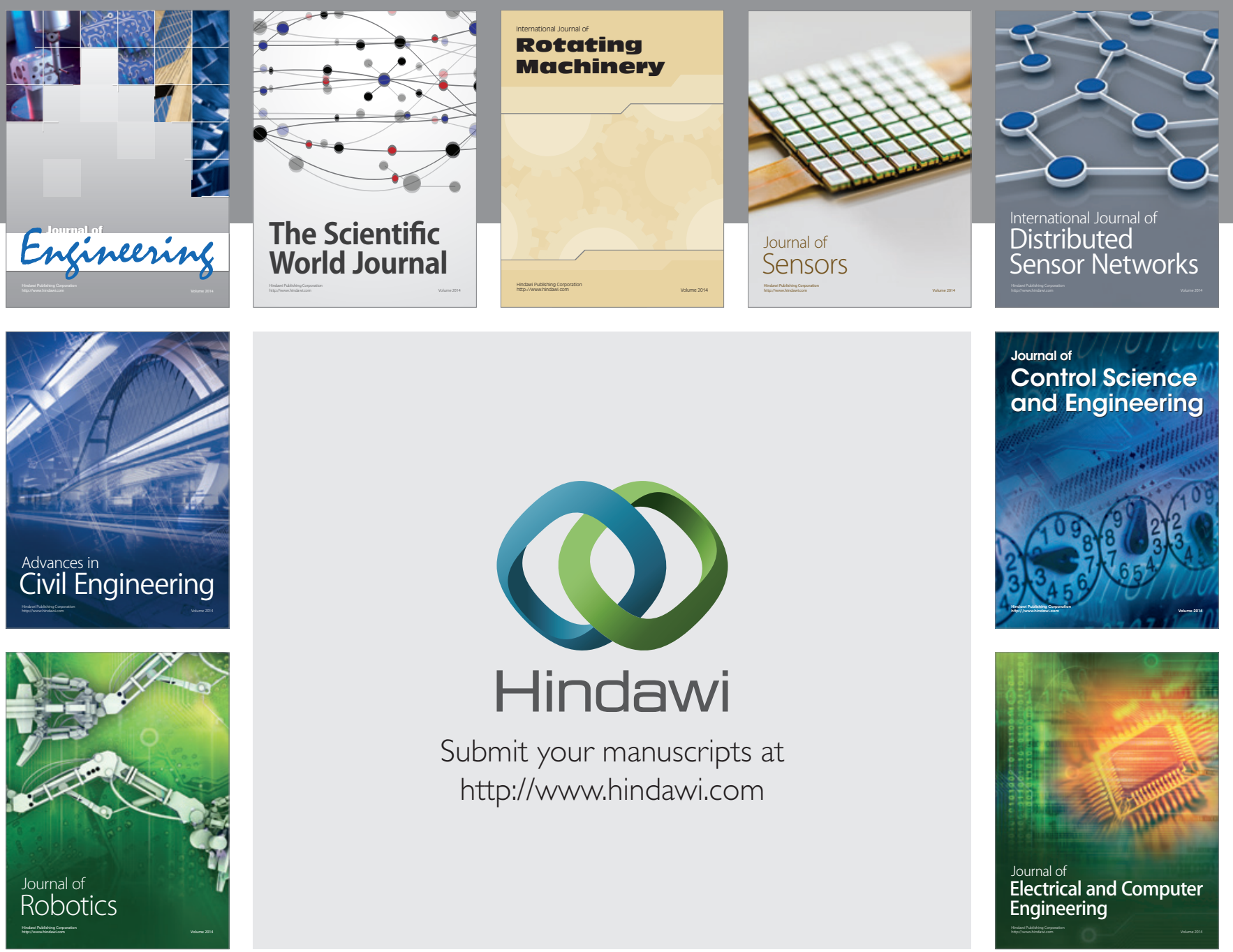

Submit your manuscripts at

http://www.hindawi.com
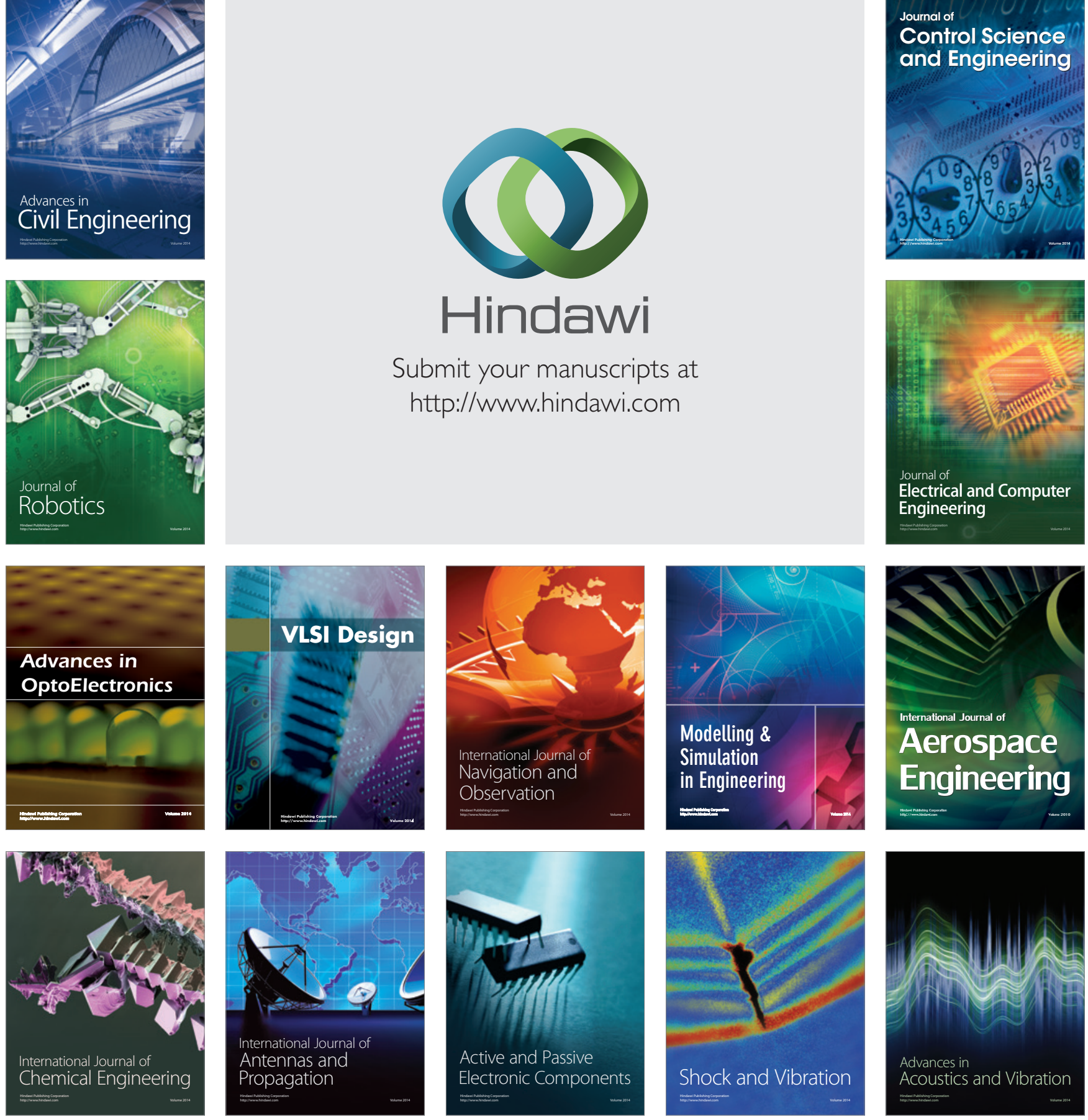